\title{
MODERNIZANDO A TAXONOMIA
}

\author{
Alessandro Rapini
}

Biota Neotropica v4 (n1) - http://www.biotaneotropica.org.br/v4n1/pt/abstract?point-of-view+BN00204012004

Recebido em: 03/09/2003

Publicado em: 05/01/2004

\begin{abstract}
Pós-graduação em Botânica, Departamento de Ciências Biológicas, Universidade Estadual de Feira de Santana, BR-116, Km 3, Av. Universitária s/n, CEP 44031-460, Feira de Santana - Bahia, Brasil. Tel./Fax: (75) 224-8033; e-mail: rapinibot@yahoo.com.br
\end{abstract}

\begin{abstract}
Modernising the Taxonomy - Taxonomy is the discipline responsible for classifying organisms, allowing fields of biology to interchange information. Nevertheless, this activity has lost prestige compared to other disciplines. This has encouraged initiatives to modernise the taxonomy, making it more precise and accessible to the general public. Some proposals imply changes in deep-rooted rules of taxonomy, such as the principle of priority, the linking of names to types and the use of taxonomic ranks. If adopted, these modifications will drastically change the development of studies dealing with biodiversity. Therefore, researchers that work in regions with high diversity like Brazil need to be aware and to be able to take a conscious position concern these proposals.
\end{abstract}

Key words: biodiversity, nomenclature.

\section{Resumo}

Modernizando a taxonomia - A taxonomia é a disciplina responsável pela classificação dos organismos, permitindo o intercâmbio de informações entre as áreas da biologia. Entretanto, essa atividade tem perdido prestígio frente a outras disciplinas. Isso tem gerado iniciativas para tentar modernizar a taxonomia, tornando-a mais precisa e acessível ao público em geral. Algumas propostas implicam modificações de normas arraigadas à prática taxonômica há décadas, como o princípio de prioridade, a associação do tipo ao nome e a utilização de ranques taxonômicos. Se aceitas, essas mudanças influenciarão significativamente o desenvolvimento de estudos relacionados a biodiversidade. É necessário, portanto, que pesquisadores que trabalham em regiões com alta diversidade biológica como o Brasil estejam cientes e possam se posicionar com propriedade frente a essas propostas.

Palavras-chave: biodiversidade, nomenclatura.

http://www.biotaneotropica.org.br 
A taxonomia é a disciplina responsável pela classificação dos seres vivos. Classificar é uma atividade intrínseca ao raciocínio humano, mas a classificação biológica tomou feições modernas apenas a partir do sistema hierárquico-binomial implantado por Lineu em 1753. Dentro de um sistema padronizado de classificação e nomenclatura passou a ser possível armazenar, resgatar e relacionar informações acumuladas em diferentes épocas e partes do mundo. Desde sua criação, o sistema de Lineu tem sofrido diversas modificações, estando atualmente composto por um conjunto de princípios e regras complexo organizado por uma comissão e publicado na forma de códigos. Nos últimos anos, a taxonomia tem perdido prestígio frente a outras áreas da ciência. A taxa de citação de artigos taxonômicos é baixa de acordo com o Science Index Citation (mas veja, por exemplo Krell 2002), a disciplina tem tido menos investimento e o número de praticantes tem decrescido (Valdecasas et al. 2000). Sua modernização, entretanto, poderia contribuir para a revitalização da disciplina (Godfray, 2002).

Dentre as características do código internacional de nomenclatura botânica (código de Saint Louis), por exemplo, estão o princípio de prioridade, desde 1842, e a associação do nome de um táxon ao tipo, aceita a partir de 1930 (McNeill 2000). A publicação de um nome funciona como um documento legal (Minelli 2003), e seu uso está diretamente associado à classificação dos tipos. Segundo o princípio de prioridade, o nome mais antigo validamente publicado prevalece no caso de sinônimos taxonômicos. Quando tipos de mais de um nome estão incluídos em um mesmo táxon, o nome da espécie que primeiro foi validamente publicada prevalece (exceto em casos de conservação e/ou rejeição aprovados pelo comitê). Trabalhos taxonômicos são geralmente volumosos, o que torna sua publicação custosa e sua distribuição mais difícil. Esse sistema lida, portanto, com uma dificuldade básica, a necessidade constante de se reportar a trabalhos antigos, muitas vezes raros e/ou pouco informativos, e tipos nem sempre bem preservados.

$\mathrm{O}$ nome de um táxon funciona com um código de acesso à sua literatura, e portanto, ao conhecimento daquele táxon, exigindo estabilidade. Ao mesmo tempo, esse nome representa uma hipótese taxonômica, daí sua instabilidade. Essa dualidade implica uma tensão característica da taxonomia (Thiele \& Yeates 2002). As dificuldades inerentes do trabalho taxonômico associadas ao desprestígio pelo qual passa a disciplina torna a tentativa de se conhecer os cerca de $90 \%$ da diversidade biológica ainda não descritos uma tarefa impraticável. A Flora Neotropica, iniciada em 1964, por exemplo, levará provavelmente mais de 300 anos para ser concluída (Prance \& Campbell 1988).

Godfray (2002) sugeriu modernizar a taxonomia através da centralização da informação taxonômica. Essa informação ficaria disponível na rede de acordo com um padrão estabelecido por um comitê, estando supervisionada por editores e revisores. A publicação eletrônica que tem sido usada quando muito como complementar, passaria a ser integral (nomes publicados apenas eletronicamente não são atualmente aceitos pelos códigos de nomenclatura). Os táxons estariam ligados a uma rede de informações completas e apenas as informações antigas relevantes seriam mantidas. Não haveria mais prioridade; a classificação correta seria aquela mantida na rede a partir da última revisão, eliminando a bagagem histórica. Posições alternativas, entretanto, permaneceriam disponíveis. Essas mudanças permitiriam a distribuição fácil e atualizada da informação, revalorizando a taxonomia e contribuindo para a captação de recursos na área.

Essa tendência já está em andamento (veja Bisby et al. 2002, Gewin 2002). A Fundação ALL Species, por exemplo pretende acelerar o trabalho taxonômico de modo a completar o conhecimento da biodiversidade global em apenas uma geração. Bancos de dados disponíveis na rede já representam uma ferramenta importante para agilizar o trabalho taxonômico. Em botânica, destacam-se por exemplo o International Plant Name Index (IPNI), englobando dados de instituições da Inglaterra, de Harvard (EUA) e da Austrália, e o $\underline{w}^{3}$ TROPICOS, mantido pelo Jardim Botânico do Missouri (EUA). Ferramentas estão sendo também desenvolvidas para facilitar o intercâmbio de dados entre diferentes grupos taxonômicos ou entre diferentes bancos de dados.

Lee (2002) acredita que publicações eletrônicas poderiam levar à anarquia e à proliferação de nomes, dificultando ainda mais o trabalho do taxomista. Entretanto, a centralização e a mediação dessas publicações por uma comissão organizadora poderia viabilizar essa informação eletronicamente de maneira adequada. A centralização da nomenclatura foi previamente sugerida através de um sistema de Registro de Nomes (um nome só seria validamente publicado quando estivesse registrado). Um dos problemas apontados nessa centralização seria o poder sobre as informações pelos responsáveis pela sua distribuição e o aumento da burocracia. Essa possibilidade foi então rejeitada pelas comissões responsáveis pelos códigos de nomenclatura botânica e zoológica em 1999. Em bactérias, no entanto, já existe uma centralização; nomes novos só são válidos quando publicados ou anunciados na International Journal of Systematic and Evolutionary Microbiology (

A centralização e implementação de um sistema eletrônico, entretanto, não resolveriam problemas relacionados a qualidade e precisão da informação taxonômica. Segundo Tautz et al. (2002, 2003), esses problemas poderiam ser solucionados com a implantação da taxonomia do DNA. A seqüência de DNA passaria a 
ser um instrumento padrão na descrição e identificação de espécies, eliminando a subjetividade associada ao uso do tipo na classificação, funcionando assim com um código de barras (Hebert et al. 2003). O DNA é uma molécula estável e poderia ser distribuída para herbários e museus através de múltiplas amostras de um mesmo indivíduo, como é feito atualmente com duplicatas de coleções herborizadas. A sequência de nucleotídeos também se adequa à publicação eletrônica, o que é comprovado pelo uso massificado do GenBank como depositário de seqüências de DNA. O custo para manutenção de um sistema de identificação a partir de DNA (1000 amostras/dia) seria equivalente aos das facilidades de um microscópio de varredura, modestos se comparados com alguns programas de genoma (Tautz et al. 2003).

Alguns problemas na aplicação de seqüências de DNA para a descrição de espécies são evidentes (veja Lipscomb et al. 2003, Mallet \& Willmot 2003, Seberg et al. 2003). Espécies são diferentes dos nomes que as representam. Nomes possuem tipo, espécies não. Espécies incluem a variação adotada pela hipótese de circunscrição daquele táxon, podendo variar conforme o grau de conhecimento ou premissas assumidas, enquanto a associação tipo-nome é técnica e assumida por convenção. Assim como características diferentes podem ser usadas para definir uma espécie, genes diferentes também poderiam ser usados, mantendo o grau de instabilidade nomenclatória característico da taxonomia. O polimorfismo genético é amplamente conhecido e o uso de sequiências poderia levar a descrição de indivíduos, e não espécies. Qual então seria o gene ideal para ser utilizado na descrição de espécies? Uma das alternativas seria utilizar mais de um gene. Quantos seria o ideal? Aparentemente, não existe uma razão clara para que o DNA seja considerado um caráter mais apropriado na definição de um táxon, e a inclusão de mais uma exigência para a descrição de espécies novas dificultaria ainda mais a tarefa já árdua e lenta de descrever a biodiversidade global, excluindo a maioria dos taxonomistas de países em desenvolvimento, aonde está abrigada a maior parte das espécies ainda não conhecida.

Outra proposta radical é a substituição dos códigos de nomenclatura pelo Filocódigo (PhyloCode), um conjunto de regras elaboradas por um consórcio de pesquisadores de renome, que tem na substituição de tipos por especificadores, no abandono das categorias taxonômicas e no registro de nomes as principais modificações para o estabelecimento de uma taxonomia filogenética. Diferente do código de nomenclatura atual, no entanto, o Filocódigo interfere não apenas na aplicação de nomes, mas também na circunscrição dos grupos, já que não permite a nomeação de grupos para e polifiléticos (Stuessy 2001).

Alterações são incorporadas no sistema de nomenclatura visando oferecer maior clareza, estabilidade e universalidade para a aplicação dos nomes (para um histórico da nomenclatura botânica, veja Nicolson 1991). O método de classificação também tem sofrido algumas alterações, desde sistemas artificiais até o atual sistema filogenético, priorizando o monofiletismo dos grupos (Backlund \& Bremer 1998). Mudanças na maneira de se organizar a biodiversidade têm sido salutar, possibilitando a adequação dos sistemas de classificação a novas premissas teóricas e necessidades práticas. Tais mudanças, no entanto, podem acarretar uma ruptura com o conhecimento acumulado durante séculos e prejudicar o trabalho taxonômico.

Como apresentado, propostas inovadoras estão despontando na taxonomia, e a implementamentação dessas alternativas poderá acelerar ou retardar o conhecimento da biodiversidade. Mudanças no método de nomenclatura e classificação não influenciarão exclusivamente o trabalho dos taxonomistas, mas de todos que utilizam informações taxonômicas condensadas em nomes científico para sua comunicação. É fundamental, portanto, que pesquisadores de países tropicais, ricos em biodiversidade como o Brasil, e que portanto serão os maiores afetados por essas mudanças, possam se posicionar de maneira consciente e participar de maneira ativa frente a possíveis renovações na taxonomia.

\section{Referências bibliográficas}

BACKLUND, A. \& BREMER, K. 1998. To be or not to beprinciples of classification and monotypic families. Taxon 47:392-399.

BISBY, F.A., SHIMURA, J., RUGGIERO, M., EDWARDS, J. \& HAEUSER, C. 2002. Taxonomy, at the click of a mouse. Nature 418:367.

GODFRAY, H.C.J. 2002. Challenges for taxonomy. Nature 417:17-19.

GWEIN, V. 2002. All living things, online. Nature 418:362363.

HEBERT P.D.N., CYWINSKA A., BALL S.L. \& DEWAARD J.R. 2003. Biological identifications through DNA barcodes. Proc. R. Soc. Lond. Ser. B 270:313-321.

KRELL, F.-T. 2002. Why impact factors don't work for taxonomy. Nature 45:957.

LEE, M.S.Y. 2002. Online database could end taxonomic anarchy. Nature 417:787-788.

LIPSCOMB, D., PLATNICK, N. \& WHEELER, Q. 2003. The intellectual content of taxonomy: a comment on DNA taxonomy. Trends Ecol. Evol. 18:65-66.

MALLET, J. \& WILLMOTT, K. 2003. Taxonomy: renaissance or Tower of Babel? Trends Ecol. Evol. 18:57-59.

MCNEILL, J. 2000. Naming the groups: developing a stable and efficient nomenclature. Taxon 49:705-720. 
MINELLI, A. 2003. The status of taxonomy literature. Trends Ecol. Evol. 18:75-76.

NICOLSON, D.H. 1991. A history of botanical nomenclature. Ann. Missouri Bot. Gard. 78:33-56.

PRANCE, G.T \& CAMPBELL, D.G. 1988. The present state of tropical floristics. Taxon 37:519-548.

SEBERG, O., HUMPHRIES, C.J., KNAPP, S., STEVENSON, D.W., PETERESEN, G., SCHARFF, N. \& ANDERSEN, N.M. 2003. Shortcuts in systematics? A comentary on DNA-based taxonomy. Trends Ecol. Evol. 18:63-65.

STUESSY, T.F. 2001. Taxon names are still not defined. Taxon $50: 185$.

TAUTZ, D., ARCTANDER, P., MINELLI, A., THOMAS, R.H. \& VOGLER, A.P. 2002. DNA points the way ahead in taxonomy. Nature 418:479.

TAUTZ, D., ARCTANDER, P., MINELLI, A., THOMAS, R.H. \& VOGLER, A.P. 2003. A plea for DNA taxonomy. Trends Ecol. Evol. 18:70-74.

THIELE, K. \& YEATES, D. 2002. Tension arises from duality at the heart of taxonomy. Nature 419:337.

VALDECASAS, A.G., CASTROVIEJO, S. \& MARCUS, L.F. 2000. Reliance on the citation index undermines the study of biodiversity. Nature 403:698.

Título: Modernizando a taxonomia

Autor: Alessandro Rapini

Biota Neotropica, Vol.4 ( number 1): 2004

http://www.biotaneotropica.org.br/v4n 1/pt/ abstract?point-of-view+BN00204012004

Recebido em: 03/09/2003

Publicado em: 05/01/2004

ISSN 1676-0603

http://www.biotaneotropica.org.br 